\title{
Intercomparisons of some dust models over West Asia
}

\author{
Amirhossein Nikfal*, Abbas Ranjbar Saadatabadi, Mehdi Rahnama, Sahar Tajbakhsh, and Mohammad Moradi \\ Atmospheric Science and Meteorological Research Centre (ASMERC), Tehran, Iran
}

\begin{abstract}
Evaluation and assessment of dust model results is of primary importance to get a better understanding of the models' performance, and therefore, enhancing the models' set up and structure. Besides some SDS-WAS dust models, two other high resolution WRF-Chem runs have been carried out for two dust episodes over the West Asia with alterations in the soil erodibility fields as one of the primary criteria of dust sources. The main aim of this article was to investigate the high resolution WRF-Chem modeling with the default and altered soil erosion, against the WMO SDS-WAS models. In this paper we investigated the application of WRF-Chem dust modeling for the region of interest (Iran), which cannot be seen entirely by the SDS-WAS models' domains. Comparisons of modelled dust surface concentrations with ground based measurements on 8 air quality stations show that the high resolution WRF-Chem could more or less lead to better predictions. For some cases, the results of the high resolution WRF-Chem unexpectedly presented a declined performance, which indicate that the improvements in the horizontal resolution and soil erodibility could not always lead to improved dust predictions, and more factors such as the model set-up and structure should be considered.
\end{abstract}

\section{Introduction}

West Asia and particularly south west of Iran frequently experiences extensive dust storms over the year. Most parts of West Asia are covered with arid and semi-arid regions, with strong winds and weak vegetation cover. The floodplains of Tigris and Euphrates rivers in Iraq are known to be the main dust source in the region and have key contribution in total dust emissions over Iraq and western Iran [1].

Over the recent years, dust modelling, including the simulations of dust transport and its effects on climate (radiative forcing) has been playing a major role in environmental research. Considering that the satellite and ground based meteorological data have many limitations in providing detailed description of atmospheric processes and dust cycle, numerical modelling could be of major importance in atmospheric and air quality research [2].

Dust emission from the soil surface is a complicated process, which incorporates various factors, including turbulent atmospheric motions in the boundary layer and aeolian processes. Aeolian processes are the results of wind erosion, including dust emission and transportation, mainly over the arid surfaces.

Dust emission fluxes in atmospheric models are mainly parameterized with some atmospheric and geological factors, such as wind speed and soil structure. Soil erodibility is one of the crucial factors in identifying dust sources, and therefore, in estimating dust emission flux from the surface [3]. Erodibility is a characteristic of soil, and related to the unconsolidated aeolian deposits, endorheic depressions, and fluvial and alluvial systems. Higher erodibility could cause a more susceptible soil to erosion and therefore, larger dust emission. The potential of each of the aforementioned units varies in their relative capability to emit dust particles, due to their geomorphological characteristics [4].

There is a global dust source function, presented by Ginoux et al. (2001), which is used in many dust models, such as WRF-Chem. This source function $S\left(Z_{\mathrm{i}}\right)$ is based on topography and estimates the probability of soil sediments, accumulated at a specific location:

$$
S\left(Z_{\mathrm{i}}\right)=\left(\frac{Z_{\max }-Z_{i}}{Z_{\max }-Z_{\min }}\right)^{5}
$$

where $Z_{\mathrm{i}}$ is the altitude that is normalized with the $Z_{\max }$ and $Z_{\min }$ heights over an area of $10^{\circ} \times 10^{\circ}$ around the ith grid point. $S$ is the erodibility factor for the ith grid of the model.

The enhancement and development of the soil erodibility factor could lead to the improvement of dust prediction results by the model [5]. In a recent research [6], a new dust source function for West Asia, named WASF (West Asia Source Function), has been developed. Satellite observations were the main tool to define WASF, which had been implemented in WRF-Chem model. Modified runs of WRF-Chem with the new WASF dust source function showed an average increase in Spearman correlation by 12-16 percent between the predicted aerosol optical thickness and the measurements (satellite retrieved aerosol optical depth).

Intercomparison between various dust models is of vital importance in evaluating the performance of dust models, especially in the regions with high frequencies of dust storms. Furthermore, developing a localized dust

* Corresponding author: anik@ut.ac.ir 

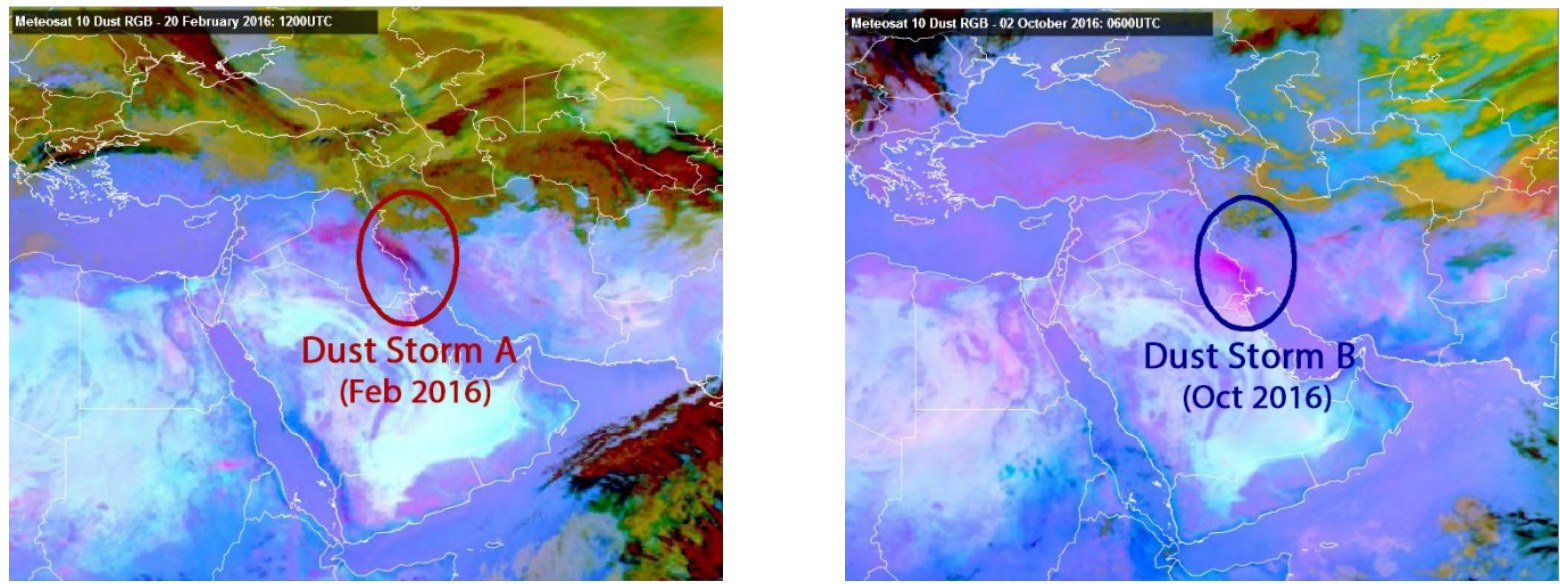

Figure 1. METEOSAT Dust RGB images for the two case studies of dust storms, drifting over the Middle East.

model for the region of interest requires an accurate assessment of various operational dust models. The Northern Africa - Middle East - Europe (NA-ME-E) Regional Center of WMO SDS-WAS (Sand and Dust Storms Warning Advisory System) which is jointly managed by several organizations such as BSC (Barcelona Supercomputing Center) and AEMET is a federation of partners to improve capabilities for more reliable sand and dust storm forecasts.

In this article, the results of several dust models, provided by the WMO SDS-WAS NA-ME-E regional centre, have been investigated for two dust episodes in 2016 over the studied region, and compared with measurements, as well as localized high resolution runs of WRF-Chem. The forecasts of SDS-WAS dust models cover parts of the West Asia and Iran. Countries in this domain can use the SDS-WAS dust models' forecasts for their own objectives. Furthermore, they can carry out separate dust modelling, with smaller domains and more accurate settings (higher resolutions, etc.) for a specific region inside the SDS-WAS dust models' domain. However, further case studies are needed to make more accurate evaluation of the performances of dust models' predictions.

\section{Data and methods}

Two dust episodes in February 20, and October 02, 2016, blowing the south west of Iran, have been selected as case studies. The area of study, which includes Khuzestan Province and its neighbours, is frequently exposed to dust storms over the year. The formation of dust plumes could be seen as pink colours in the METEOSAT Dust RGB images (Fig. 1). The same areas which are encircled on the images represent the two dust episodes, which have been considered as case studies. Several operational dust models participated in the WMO SDS-WAS program for model intercomparison, have been evaluated to examine the capabilities of various numerical atmospheric models in predicting dust surface concentration. In addition to the operational dust models, some high resolution WRFChem simulations were carried out for the case studies over Iran. Table 1 shows the primary specifications of the models, used in this article. The last two models correspond to high-resolution dust modelling with the
WRF-Chem, to be compared with the operational dust models. Dust erosion field in WRF-Chem-WASF is partly changed in an attempt to correct the default Ginoux dust source for the region. This new dust source has been compared with the default erosion field in WRF-Chem, which is based on Ginoux et al. (2001).

Table 1. Specifications of the evaluated dust models.

\begin{tabular}{|c|c|c|c|}
\hline Model & Resolution & Institution & Domain \\
\hline DREAM8b_V2 & $1 / 3^{\circ} \times 1 / 3^{\circ}$ & BSC & Regional \\
\hline $\begin{array}{c}\text { NMMB/BSC- } \\
\text { Dust }\end{array}$ & $1 / 3^{\circ} \times 1 / 3^{\circ}$ & BSC & Regional \\
\hline WRF-Chem & $0.19^{\circ} \times 0.22^{\circ}$ & NOA & Regional \\
\hline $\begin{array}{c}\text { Multi-model } \\
\text { MEDIAN }\end{array}$ & - & BSC & Regional \\
\hline DREAM-MACC & $1 / 3^{\circ} \times 1 / 3^{\circ}$ & SEEVCCC & Regional \\
\hline GEOS & $0.25^{\circ} \times 0.31^{\circ}$ & NASA & Global \\
\hline NGAC & $\sim 1^{\circ}$ & NCEP & Global \\
\hline $\begin{array}{c}\text { High resolution } \\
\text { WRF-Chem }\end{array}$ & $10 \mathrm{~km} \times 10 \mathrm{~km}$ & - & Regional \\
\hline $\begin{array}{c}\text { High resolution } \\
\text { WRFChem- } \\
\text { WASF }\end{array}$ & $10 \mathrm{~km} \times 10 \mathrm{~km}$ & - & Regional \\
\hline
\end{tabular}

Figure 2 shows the domains of the high-resolution WRF-Chem dust modelling, with $30 \times 30 \mathrm{~km}$ grid resolution for the main domain, and $10 \times 10 \mathrm{~km}$ for the subdomain (d02). Setting and creating model domains in WRF are carried out by the WRF Pre-processing System

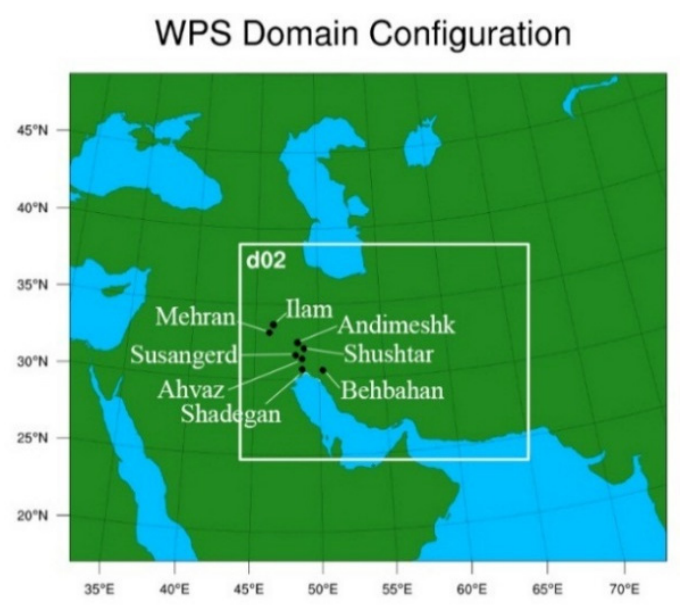

Figure 2. Model domains of the high resolution WRF-Chem. 

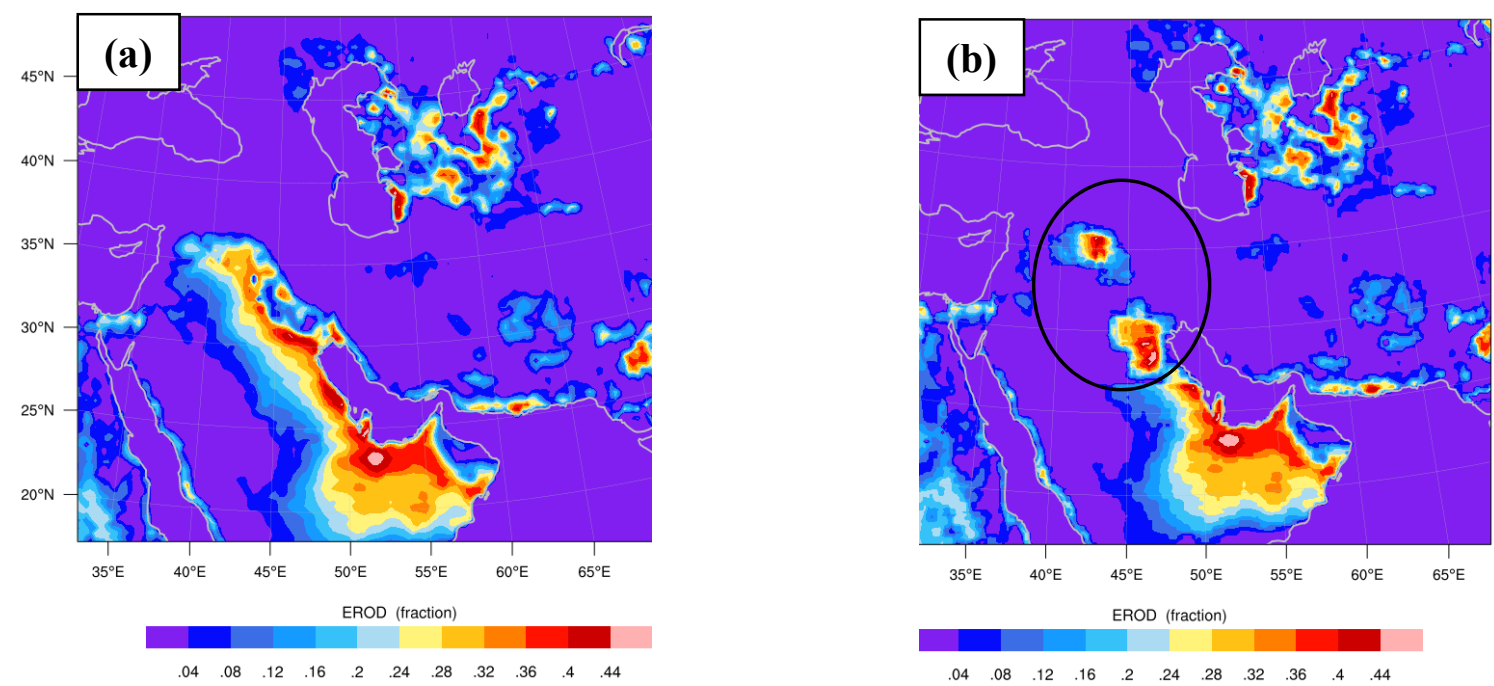

Figure 3. Dust sources (soil erodibility) for (a) default WRF-Chem, and (b) partly replaced by WASF dust sources (encircled).

(WPS), and the ERA-Interim global atmospheric reanalysis data were used as the initial and boundary conditions. The second domain is extended over Iran. Furthermore, the geographical locations of 8 air quality stations are marked on the map in Fig. 2, which provide the measurement data for the evaluations of the models' results.

For the sake of better comparisons, and considering that the model domains of SDS-WAS models are different from that of the high resolution WRF-Chem dust modelling, all the downloaded SDS-WAS model outputs with rectilinear grid structure have been re-gridded to the high resolution $(10 \times 10 \mathrm{~km}) \mathrm{WRF}-\mathrm{Chem}$ model grids with curvilinear structure. These re-gridding procedures enable the so-called "pattern correlation" between various model outputs and therefore, better evaluations of the results. It should be mentioned that the re-gridding from a coarse grid to a finer one is not recommended, because a model that is run at a coarser grid cannot be expected to resolve the same features that a model with fine resolution can be expected to capture. Hence, the validation results for this re-gridded model output could be very limited. However, we preferred to re-grid the SDS-WAS model results with larger domains on our high resolution WRF-Chem results with smaller domain, because it was more straightforward. Re-gridding the small domain on the larger ones, would have caused lots of grid points with missing values. Furthermore, the new re-gridded domains have been used only for the so-called map correlations, and the other statistical scores (RMSE, etc.) displayed on the Taylor diagrams have been directly calculated (interpolated) from the original models' outputs.

Figure 3 shows the difference between soil erosion maps in the two high resolution WRF-Chem outputs, over the main domains. Figure 3 a illustrates the default erosion map over the model domain, while Fig. $3 b$ has been changed and partly replaced by the newly defined West Asia Source Function (WASF), which specifies dust sources for the model. The WASF dust function is significantly different from the default global dust sources for the same region. The preparation of WASF is based on multiyear analysis of satellite data, while the default global dust sources in WRF-Chem is based on topography.

\section{Results}

Dust surface concentrations have been extracted from the models' outputs over the single points (air quality stations), depicted in Fig. 2. Time series of dust concentrations in the two stations of Ahvaz and Ilam are shown in Fig. 4, which indicates the high resolution WRFChem (red line) with the best performance for these two points in comparison to measurements (black line). The high resolution WRF-Chem-WASF, unexpectedly did not show improved results for Ahvaz station (February case study), but it was improved for the Ilam station, for the October case study.

Other model results show more or less the same results. Generally, overestimations of the models for both cases are marked on Fig. 5. Within the selected SDSWAS dust models, there are two global dust models, named NASA-GEOS and NCEP-NGAG. Figure 5 shows a weak performance in the modelling of dust concentrations for the NASA-GEOS model. Since, NASA-GEOS is a global dust model, it is expected to show less accurate results for dust concentrations in comparison to other regional SDS-WAS models, as well as the results of the high resolution WRF-Chem. For the other global dust model (NCEP-NGAC), the results were quite different. In Several air quality stations, especially Andimeshk and Susangerd stations, the global model NCEP-NGAC shows a high performance in comparison to other selected global and regional models.

Figure 6 shows surface dust concentrations in a specific time, simulated by the high resolution WRFChem and WRF-Chem-WASF, for the February 2016 dust storm. West parts of the domain (encircled), shown in Fig. 6 evidently differ in the distribution of the simulated dust. But other parts are quite similar in dust concentration. This pattern is expected considering the distribution of dust sources in Figs. $3 a$ and $3 b$.

Several Taylor diagrams for each of the 8 stations are shown in Fig. 5, comparing the models' outputs with the 

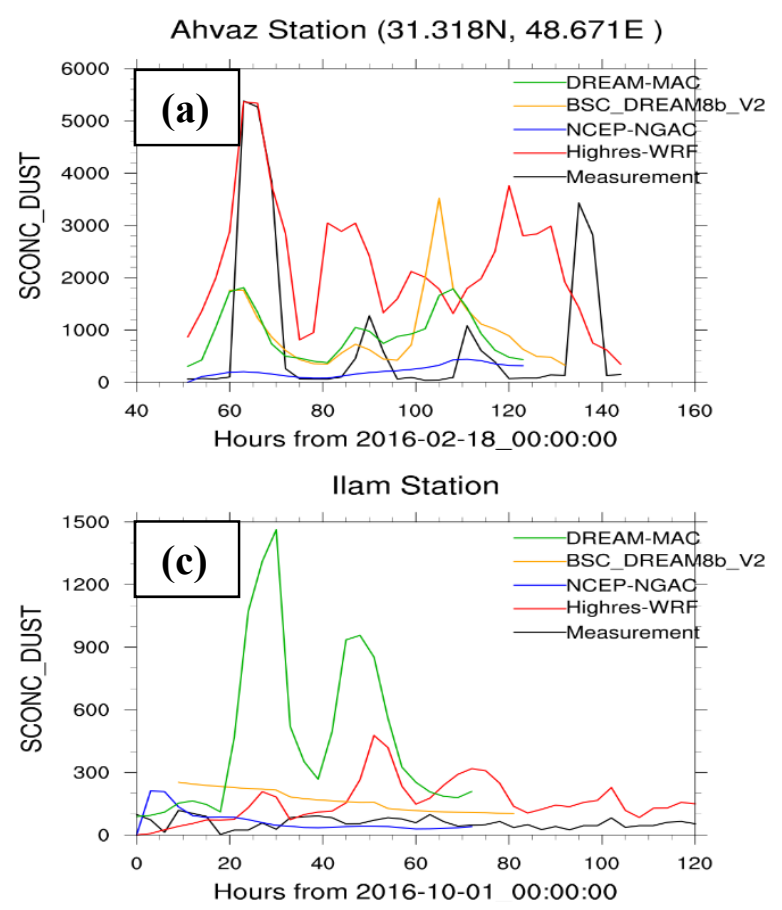

Ahvaz Station $(31.318 \mathrm{~N}, 48.671 \mathrm{E})$

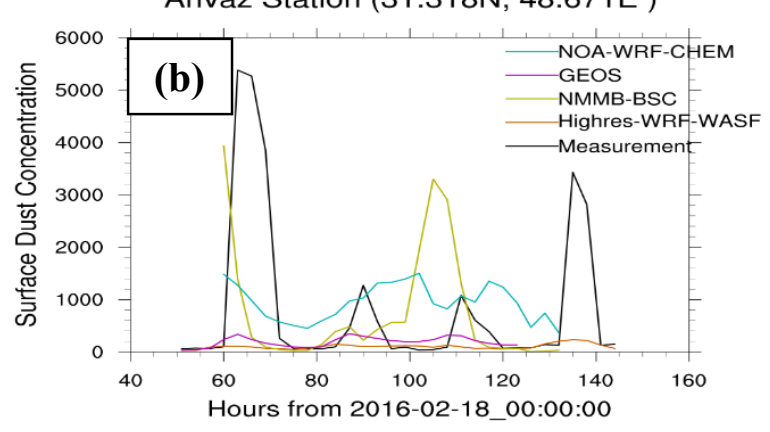

Ilam Station

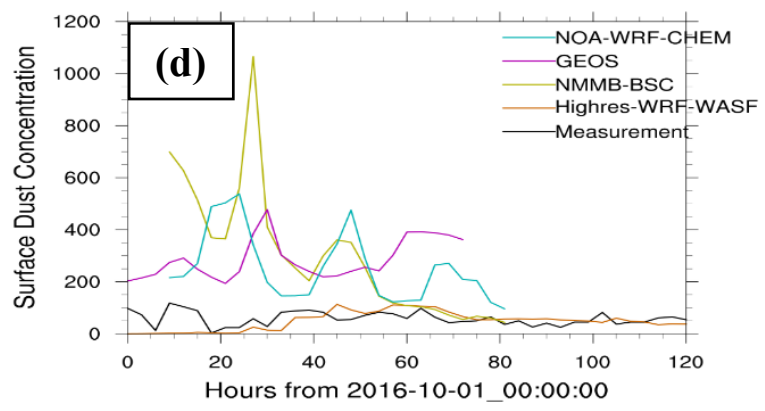

Figure 4. Time series of the dust products for (a) and (b) Ahvaz station - Feb 2016, and (b) and (c) Ilam station - Oct 2016.

observation data. A Taylor diagram, presents the statistical parameters, as a grade of accuracy to each of the models' output. Two case studies for the dust storms on February and October 2016 are determined by the red and blue spots, respectively. The red spots with black dot inside, correspond to the high resolution WRF-Chem simulation results in comparison to the observations.

Referring to Fig. 5a, the weak results of all forecasts for the October dust storm (blue spots) are obvious. However, results for the February dust storm (red spots) are generally more acceptable. Due to the similarity of the models' results for the October dust storm, the labels of the blue dots have been omitted. The unexpected issue is that the high resolution WRF-Chem-WASF does not show an improved result for the predicted dust concentration, compared with the high resolution WRFChem with default dust sources. Although the high resolution WRF-Chem (dark red spots) is not always indicative of the best prediction for the surface dust concentration, but on average, considering the models' (a)
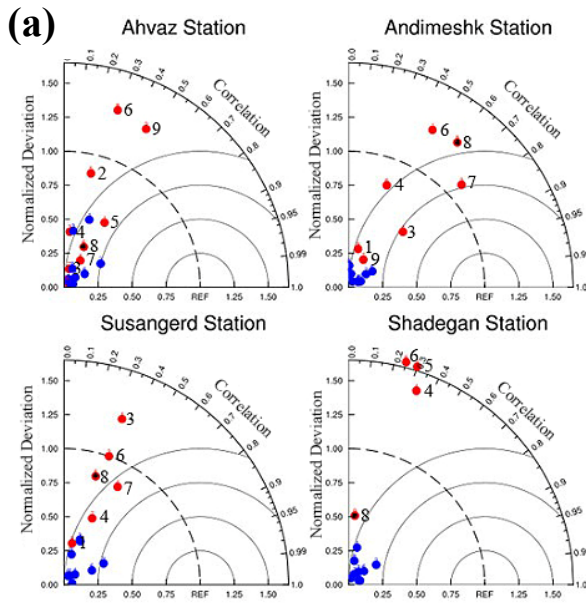

llam Station

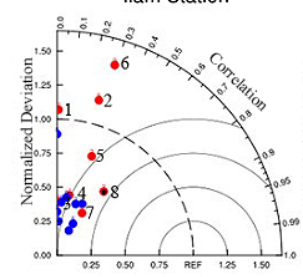

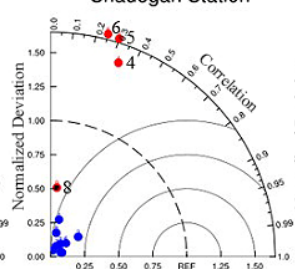

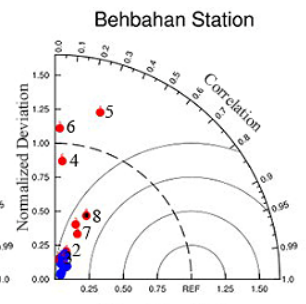

Shushtar Station

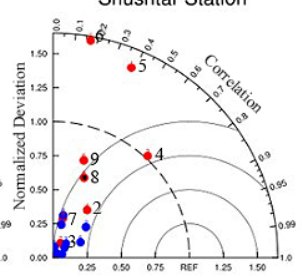

-Dust B (Oct)
-Dust A (Feb)

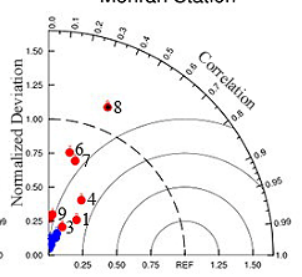

(b) Models' intercorrelations (Oct 2016)

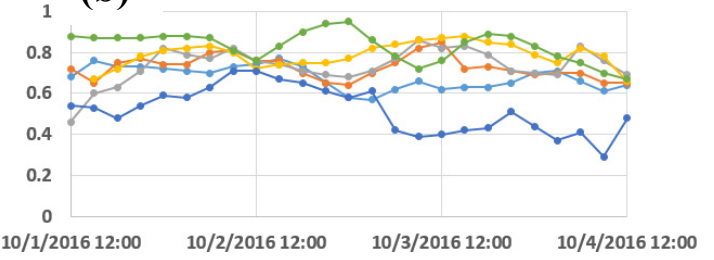

(c) Models' intercorrelations (Feb 2016)<smiles>CCC</smiles>

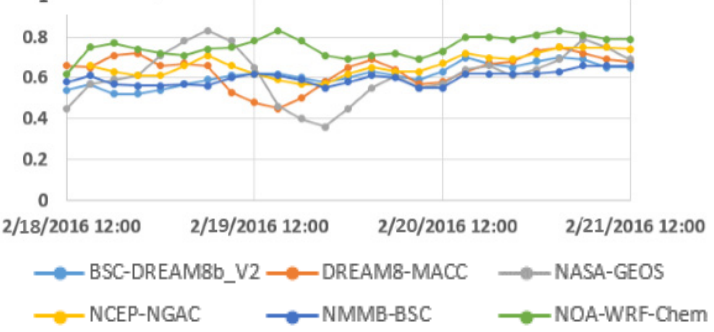

Figure 5. (a) Taylor diagrams for the 8 air quality stations, to compare 9 dust models with observations, (b) and (c) time series of pattern correlations between the high resolution WRF-Chem results and other WMO SDS-WAS dust models. 


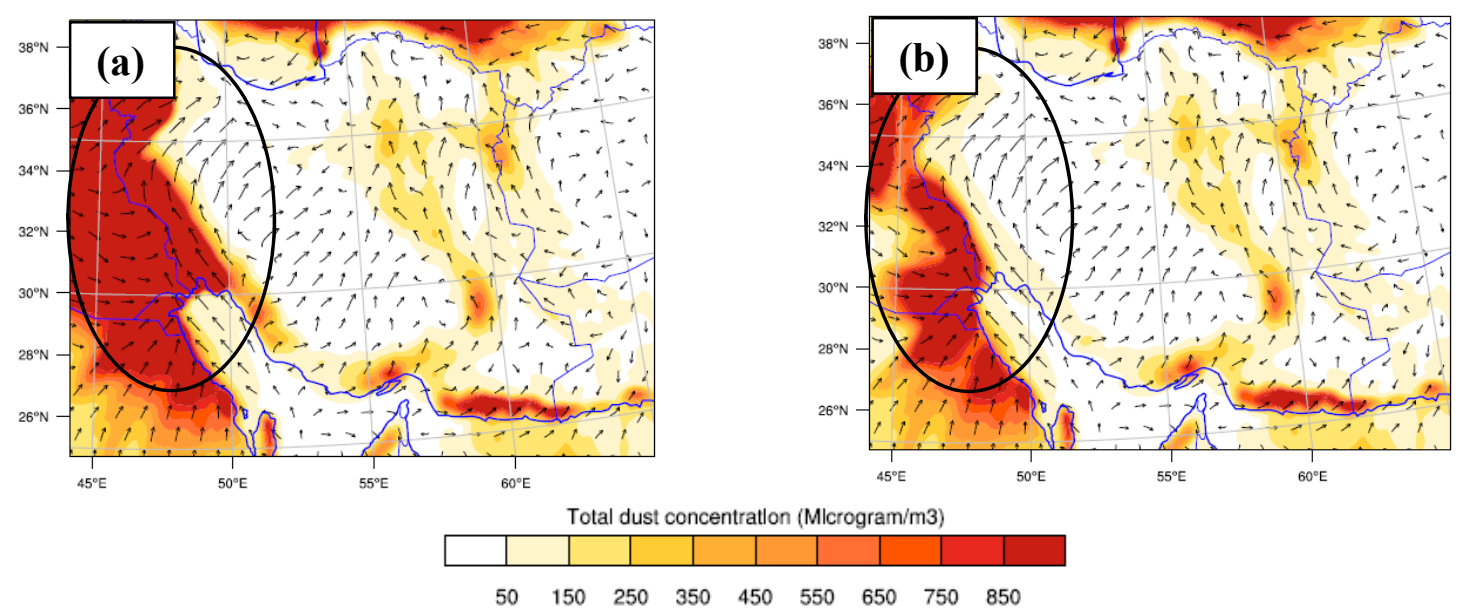

Figure 6. Surface dust concentrations from high resolution WRF-Chem for the February 2016 dust storm for (a) default WRF-Chem dust sources, and (b) WASF dust sources.

RMSE values for the February dust storm (red dots), the high resolution WRF-Chem forecasts are preferable to other results.

Figures $5 \mathrm{~b}$ and $5 \mathrm{c}$ show the time series of the intercorrelations (pattern correlations) between the high resolution WRF-Chem and the rest of WMO SDS-WAS dust models for the two dust storms. The concept of intercorrelation is the Pearson coefficient of linear correlation for the same locations between two maps (forecast and observation), for different times (along a time series). Pattern correlation could be defined as the correlation of the corresponding grid points in the two maps. Considering that the NOA-WRF-Chem and the high resolution WRF-Chem are both the same models, even with different grid resolutions and model settings (microphysics, PBL schemes, etc.) they show the highest pattern correlation with each other, which is higher than the pattern correlation between the high-resolution WRFChem and any other SDS-WAS models' outputs.

\section{Conclusion}

In this paper several operational dust models, run by various research institutions, have been investigated against the WRF-Chem model results for dust concentration. The sensitivity of regional versus global dust models in simulating dust concentration has shown that although regional dust models are expected to be technically more complex than those of global dust models, but for some cases (as presented in this paper), the global model's result could have better simulation for dust surface concentration. Moreover, the sensitivity of soil erodibility factor, which represents dust sources, has been investigated by considering the default WRF-Chem dust source function (Ginoux) against a reformed dust source (WASF) for West Asia. Although the WASF dust source was created in an attempt to determine the dust sources in the region more accurately, the default WRFChem dust source function showed more reasonable results for our simulations. The correction of dust sources alone cannot always lead to more accurate dust predictions by the complex atmospheric models.
Explicit numerical modelling with the spatial resolution of $10 \mathrm{~km}$ is not applicable and parameterization should be carried out. But in operational forecasts for meso-scale regions, it is not feasible for the most cases to run the model with resolutions of $5 \mathrm{~km}$ or less. Assuming that the observation data is collected with minor errors, results show that the increase of the model's horizontal resolution alone, could not guarantee a significant improvement in dust prediction. Furthermore, due to the methodology which has been used in creating WASF dust source function, map of soil erosions based on the frequency of dust storm occurrences could be erroneous, because the accurate determination of the fresh dust outbreaks which is the key factor in identifying the dust emission sources, is a highly complicated task. Furthermore, integrating a new dust source function which is prepared with a different approach in comparison with the default dust source (Ginoux dust source) in WRF-Chem could cause incompatibility.

\section{References}

1. Seyed Omid Nabavi, Leopold Haimberger, and Cyrus Samimi, Climatology of dust distribution over West Asia from homogenized remote sensing data, Aeolian Research 21 (2016)

2. S. Nickovic, Modeling of dust process for the Saharan and Mediterranean area, The impact of desert dust across the Mediterranean (pp. 15-23. Springer, Dordrecht 1996)

3. Paul Ginoux, Mian Chin, Ina Tegen, Joseph M. Prospero, Brent Holben, Oleg Dubovik, and ShianJiann Lin, Sources and distributions of dust aerosols simulated with the GOCART model, Journal of Geophysical Research: Atmospheres 106, no. D17 (2001)

4. Joanna E. Bullard, et al., Preferential dust sources: A geomorphological classification designed for use in global dust-cycle models, Journal of Geophysical Research: Earth Surface 116, F4 (2011) 
5. S. Basart, C. Pérez, S. Nickovic, E. Cuevas, and J.M. Baldasano, Development and evaluation of the BSCDREAM8b dust regional model over Northern Africa, the Mediterranean and the Middle East, Tellus B 64, 18539, doi:10.3402/tellusb.v64i0.18539 (2012)

6. Seyed Omid Nabavi, Leopold Haimberger, and Cyrus Samimi, Sensitivity of WRF-chem predictions to dust source function specification in West Asia, Aeolian Research 24 (2017) 